\title{
La Comunicación Científica Oral de los Profesionales: su Significación
}

Darlén Méndez Lloret ${ }^{1}$, Silvia Alonso Paz ${ }^{1}$

1 Universidad Central Marta Abreu de Las Villas, Santa Clara, Cuba.

E-mails:

darlenm@uclv.edu.cu (DML), silviaa@ uclv.edu.cu (SAP)
El perfeccionamiento de la comunicación científica oral de los profesionales es primordial en la actualidad, pues sin este no se podrían transmitir los avances enmarcados en el área científica. Este tipo de comunicación se realiza mediante el lenguaje verbal oral, el cual participa en los procesos de construcción conjunta de los conocimientos.

Se le debe prestar especial interés al desarrollo de habilidades comunicativas para la comunicación científica oral, porque en su construcción se emplea un determinado código y sus recursos lingüísticos tienen un alto grado de especificidad.

En la esfera universitaria los profesionales realizan actividades en cuanto a la labor científica que son de suma importancia, como por ejemplo: predefensas y defensas de maestrías y doctorados, participación en tribunales para la predefensa y defensa de tesis, presentación de ponencias, elaboración de poster para presentar en eventos al igual que conferencias, entre otras actividades; todas ellas requieren de alta preparación. En estas actividades se evidencian dificultades en la comunicación científica oral de los profesionales, los cuales no siempre comunican coherentemente los resultados en la labor que desempeñan.

Estudios realizados demostraron las siguientes deficiencias en la comunicación de los resultados científicos: vocabulario pobre o escaso, incoherencia en los planteamientos, uso excesivo de muletillas, errores en el uso de la terminología científica, errores en la morfología y la sintaxis, escasa expresión mímica, diapositivas con mucha información, alta dependencia del PowerPoint, omisión de la introducción al tema, de la situación problémica, de los antecedentes y de la justificación de la investigación, uso de vocablos populares y/o vulgares, entre otras.

La fluidez y la exactitud son indicadores que posibilitan al profesional la autovaloración en la comunicación científica oral.

Sin embargo, existen aspectos que se deben tener en cuenta para comunicar los resultados científicos. Por un lado, la naturalidad y la sencillez, son cualidades difíciles de lograr en la comunicación científica oral; se requiere de una expresión viva y espontánea lo que no implique vulgaridad o descuido, esto se logra con preparación y ensayo. El profesional se debe asegurar de que el mensaje llegue al auditorio de una manera comprensible.

Por otro lado, claridad, precisión y verificabilidad son elementos que no pueden obviarse en la exposición de resultados científicos, el lenguaje científico es claro y preciso por naturaleza y los resultados que se obtengan en las investigaciones deben ser verificados antes presentarlos a la comunidad científica.

En la comunicación científica oral lo recomendable es respetar la coherencia y la cohesión del discurso. Esto no impide que cada cual tenga su estilo y utilice los recursos que considere necesarios; además, deben desarrollarse habilidades lingüísticas e investigativas. 